\title{
Intraventricular glioblastoma
}

\author{
Hassan Baallal*, Mouhcine Salami, Ali Akhaddar, Miloud Gazzaz and Brahim El Mostarchid \\ Department of Neurosurgery, Mohammed V Military Teaching Hospital, University of King Mohammed V Souissi, Rabat, Morocco
}

\section{Introduction}

Glioblastoma (World Health Organization [WHO] grade IV), one of the most malignant central nervous system (CNS) cancers in children and adults, is characterized by architectural diversity and cellular heterogeneity [1]; it is a common primary brain tumor, which constitutes about $25 \%$ of all intracranial tumors in adults [2,3]. Being known as the most malignant primary brain tumor, GBM may arise theoretically anywhere within the central nervous system (CNS) [2,3]. However Glial tumors mostly present in cerebral hemispheres (86\%), only a very small percent of them (2.2\%) present in the ventricles [4]. We present a case of an Intraventricular Glioblastoma, which has been managed with stereotactic biopsy and adjuvant chemoradiotherapy. We discuss clinical, radiological, therapeutic aspects of this rare pathology, with a literature review.

\section{Case report}

A 13-year-old male child, was referred to us with headache, vomiting and left-sided hemiparesis which had progressed in 1 week. On examination, the child was conscious, alert and cooperative, having normal higher mental functions. There was bilateral papilloedema, left sixth nerve paresis and left spastic hemiparesis with power grade 2/5. Plantars were bilateral extensor. On Magnetic resonance imaging (MRI) examination of the patient, revealed an intraventricular solid and cyst lesion, rim-enhancing, $58 \mathrm{~mm} \times 51 \mathrm{~mm}$ sized heterogeneous mass lesion in the third ventricle infiltrative pattern and around the medial occipital ventricular wall and spreading into the splenium of corpus callosum and septum pellucidum with obstructive hydrocephalus (Figure 1).

A stereotactic biopsy from the mass lesion and insertion of a ventriculo-peritoneal (V-P) shunt. The surgery was successful without any complication. Frozen-section result was compatible with highgrade glioma. Post-operative course of the patient was uneventful. Histopathological diagnosis was glioblastoma with nuclear atypia, endothelial proliferation, and necrosis (hematoxylin and eosin stain). Necrosis was seen with the pseudopalisading pattern of malignant cells. This is a high-grade glial neoplasm (Figure 2).

After operation, the symptoms of obstructive hydrocephalus were progressively improved. One week after the operation.

His family refused concomitant chemoradiotherapy with temozolomide for the reason of economic status. He had some memory disturbance and mild hemiparesis.

\section{Discussion}

GBM is the most common and the most malignant primary CNS tumor in adults. This WHO Grade 4 tumor shows nuclear atypia, high mitotic index, endothelial proliferation and necrosis [5]. GBM constitutes approximately $25 \%$ of all intracranial tumors and $50 \%$ of all glial tumors in adults [1,3,5]. Glioblastoma incidence has been reported between 0.59 and 3.69 in 100,000 persons [6].

Although capable of arising anywhere in the CNS, these tumors mainly present as a frontotemporal lesion (63\%) of the cerebral cortex [7]. But, intraventricular glioblastoma multiforme (GBM) is relatively rare and is usually found predominantly in the frontal horn or body. We did a PubMed search using the keywords "intraventricular GBM".

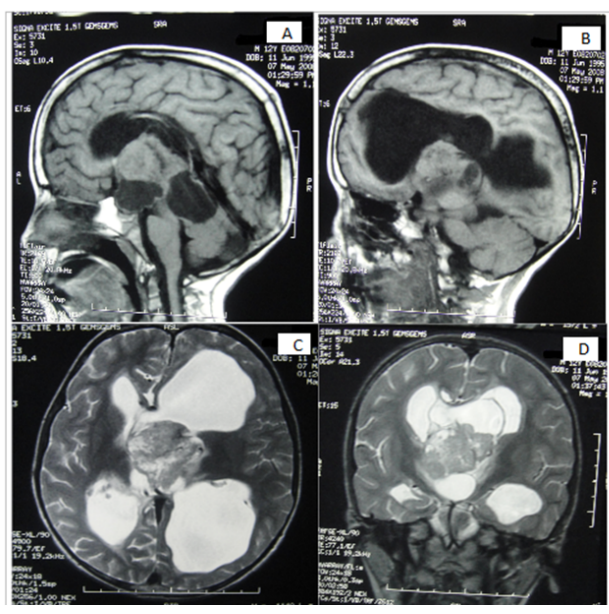

Figure 1. (A;B) Preoperative sagital T1 magnetic resonance image (MRI) showing intraventricular masse solid isointense and cyst lesion, $58 \mathrm{~mm} \times 51 \mathrm{~mm}$ sized mass lesion. (C;D) axial and Coronal T2 magnetic resonance image (MRI) showing heterogeneous solid and cyst lesion in the third ventricle with obstructive hydrocephalus.

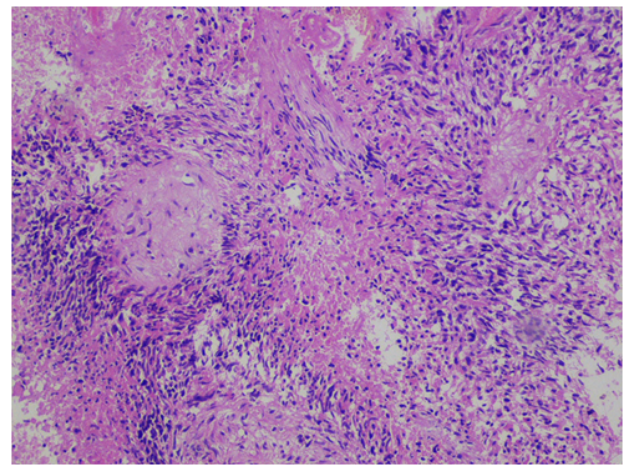

Figure 2. Histopathological appearance of the tumor shows necrosis, atypical nuclei and endothelial proliferation. Hemotoxilen \& Eosin $(\mathrm{H} \& \mathrm{E})$, original magnification $\times 100$.

Correspondence to: Hassan Baallal, Department of Neurosurgery, Mohammed V Military Teaching Hospital, University of King Mohammed V Souissi, Rabat, Morocco, E-mail: baallalnch@gmail.com

Received: June 27, 2016; Accepted: July 17, 2016; Published: July 20, 2016 
We investigated the results which contain related case reports or case series. We found out only 21 cases of intraventricular GBM reported to date $[2,8]$. Lee and Manzano stated that the intraventricular GBM may arise from the neuroglial cells of septum pellucidum or fornix. Especially, fornix and the limbic system due to their close relationship with the ventricular system have been postulated as the origin of the ventricular GBM formation [2]. Kim et al. underlined the importance of subependymal zone and the pluripotent stem cells within [5]. We also think that abnormal glial proliferation of neural stem cells might be the cause of intraventricular occurrence of GBM. Contemporary classification of lesions affecting the ventricular system categorize these lesions as primary and secondary; primary tumors originate from structures within the ventricular system, while secondary tumors originate from structures adjacent to the ventricular wall, ultimately invading into the ventricle; the authors hypothesize that the origin of tumor in this case was the neuroglial cells of the white matter in the subventricular area. This periventricular glioblastoma may have grown into the ventricle by transependymal invasion and infiltrated into surrounding structures

A less commonly cited hypothesis states that there may have been a primary GBM elsewhere in the brain, and the tumor cells subsequently seeded to the third ventricle via the cerebrospinal fluid [8]. This possibility is also unlikely in this case, given the lack of radiographic evidence for any other neoplasms in the brain or cervical, thoracic, and lumbar spine.

A lesion that originates from the ventricular wall or from the structures within the ventricle is considered primary ventricular tumor and a lesion that originates from the adjacent brain parenchyma and exophytically grows into the ventricle is considered secondary ventricular tumor [9].

In addition to these case reports some series may contain additional cases of intraventricular GBM; for example, a series of 112 patients with lateral ventricle tumors by Gokalp et al. contains five cases of GBM10. Secer et al. presented nine cases of intraventricular GBM and stated that a total of 46 cases of lateral ventricle tumors were treated at their institution during the study period [2]. The majority of the intraventricular tumors are benign and only $13 \%$ were reported as malignant lesions, including GBM, metastatic carcinoma, melanoma, etc [7]. On the other hand, in a relatively large series of 267 patients with GBM by Stark et al. there was not even a single case of intraventricular GBM. The true incidence of intraventricular GBM among all intracranial tumors or among all GBM is still uncertain or varies greatly, but it is not wrong to say that these lesions are relatively rare.

Compared to parenchymal gliomas, ventricular gliomas expand slowly within the ventricular system and cause symptoms related to compression or obstruction.

Thus, a patient with a ventricular glioma may present with hydrocephalus or symptoms related to compression of nearby eloquent structures [10]. Headache, elevated intracranial pressure and visual defects are the most common symptoms. Less frequently, patients may present with focal motor deficit, nausea, disorientation, memory loss and ataxia. However, the interval between symptom onset and presentation is short, ranging between weeks and months [11].

Symptoms caused by obstructive hydrocephalus in this case were consistent with a large ventricular tumor. Magnetic resonance imaging is useful for both diagnostic and therapeutic aspects. Before ascribing glioblastoma as pure 3 rd ventricle neoplasm, its possible interdigitating nature with surrounding brain parenchyma (thalamus, caudate nucleus) should be carefully inspected on MRI [12]. Given the location of the mass at the fornix, near the foramen of Monroe, the radiographic differential diagnosis for this case included central neurocytoma, subependymal giant cell astrocytoma (commonly associated with tuberous sclerosis), or an intraventricular meningioma [13]. Despite microscopic total surgical removal, radiotherapy and chemotherapy, the prognosis is worst among all intracranial malignancies with a median survival of 25-35 weeks [14]. Although glioblastoma in children remains a deadly cancer, this pattern of aggressive tumour behaviour has rarely been reported in previous studies. Spontaneous, symptomatic haemorrhage was found in less than $10 \%$ of paediatric high-grade gliomas, including glioblastoma [15]. Leptomeningeal dissemination at diagnosis was described in approximately $5 \%$ of highgrade gliomas in children [16], and only a few case reports described dissemination of glioblastoma through a VP shunt outside the CNS in children [16].

\section{Conclusion}

Intraventricular Glioblastoma is extremely rare and can affect younger individuals including children. This malignant tumor should be included in the differential diagnosis of intraventricular lesions especially in the lateral ventricles. Although MRI is very useful in detection of the lesion, definitive diagnosis depends on histopathology due to many other different neoplasms that may present in the third ventricle Management of obstructive hydrocephalus and Radical surgical resection giving radiotherapy with chemotherapy after histopathological diagnosis is safe and effective therapeutic approach.

\section{References}

1. Kleihues P, Burger PC, Aldape KD, Brat DJ, Biernat W, et al. (2007) Glioblastoma In: Louis DN, Ohgaki H, Wiestler OD, Webster WK (Eds.), WHO Classification of Tumours of the Central Nervous System (4thedn), Lyon: IARC Press; 33-49.

2. Lee TT, Manzano GR (1997) Third ventricular glioblastoma multiforme: case report Neurosurg Rev 20: 291-294. [Crossref]

3. Secer HI, Dinc C, Anik I, Duz B, Gonul E (2008) Glioblastoma multiforme of the lateral ventricle: report of nine cases. Br J Neurosurg 22: 398-401. [Crossref]

4. Larjavaara S, Mäntylä R, Salminen T, Haapasalo H, Raitanen J, et al. (2007) Incidence of gliomas by anatomic location. Neuro Oncol 9: 319-325. [Crossref]

5. Guibaud L, Champion F, Buenerd A, Pelizzari M, Bourgeois J, et al. (1997) Foetal intraventricular glioblastoma: ultrasonographic, magnetic resonance imaging and pathologic findings. J Ultrasound Med 16: 285-8.

6. Ostrom QT, Gittleman H, Stetson L, Virk SM, Barnholtz-Sloan JS (2015) Epidemiology of gliomas. Cancer Treat Res 163: 1-14. [Crossref]

7. Ribalta T, Fuller GN (2003) Brain tumors: an overview of histopathologic classification In: Winn HR (Ed.), Youman's neurological surgery. $\left(5^{\text {the }} \mathrm{dn}\right)$, Philadelphia: Saunders; 661-72.

8. Seker A, Ozek MM (2006) Congenital glioblastoma multiforme. Case report and review of the literature. J Neurosurg 105: 473-479. [Crossref]

9. Dumont AS, Farace E, Schiff D, Shaffrey ME (2003) Intraventricular gliomas Neurosurg Clin N Am 14: 571-591. [Crossref]

10. Gökalp HZ, Yüceer N, Arasil E, Deda H, Attar A, et al. (1998) Tumours of the lateral ventricle. A retrospective review of 112 cases operated upon 1970-1997. Neurosurg Rev 21: 126-137. [Crossref]

11. Park P, Choksi VR, Gala VC, Kaza AR, Murphy HS, et al. (2005) Well-circumscribed, minimally enhancing glioblastoma multiforme of the trigone: a case report and review of the literature. AJNR Am J Neuroradiol 26: 1475-1478. [Crossref]

12. Pendl G, Oztürk E, Haselsberger K (1992) Surgery of tumours of the lateral ventricle. Acta Neurochir (Wien) 116: 128-136. [Crossref]

13. Prieto R, Pascual JM, Roda JM (2006) Third ventricle glioblastoma. Case report and 
review of literature. Clin Neurol Neurosurg 108: 199-204. [Crossref]

14. Stark AM, Nabavi A, Mehdorn HM, Blömer U (2005) Glioblastoma multiforme-report of 267 cases treated at a single institution. Surg Neurol 63: 162-169. [Crossref]
15. Wakai S, Yamakawa K, Manaka S, Takakura K (1982) Spontaneous intracranial hemorrhage caused by brain tumor: its incidence and clinical significance. Neurosurgery 10: 437-444. [Crossref]

Copyright: (02016 Baallal H. This is an open-access article distributed under the terms of the Creative Commons Attribution License, which permits unrestricted use, distribution, and reproduction in any medium, provided the original author and source are credited. 